\title{
Türkiye Türkçesinde Eş Anlamlılık ve Örtmece (Tabu) Kelimelerin Eş Anlamlılık İçindeki Yeri
}

\author{
Halil İbrahim ÖZDEN
}

Karamanoğlu Mehmet Bey Üniversitesi, Sosyal Bilimler Enstitüsü, KARAMAN

\begin{abstract}
Özet
Bu çalışmada Anlam Bilimi’nin inceleme alanlarından biri olan eş anlam ve örtmece kelimeler üzerinde durulmuştur.

Dil araştırmalarında "anlamdaş, eş manalı, eş anlamlı, müteradif, sinonim”" terimleriyle karşılanan eş anlamlılığın tanımı genellikle sözlüksel bağlamda yapılmaktadır. Üzerinde birçok çalışma yapılmasına rağmen eş anlamlılık, araştırmacılar tarafından sorunları olduğuna inanılan ve çözüm bekleyen konulardan biridir. Sözlüklerde "anlamları aynı olan kelimeler" olarak tanımlanan eş anlamlı kelimelerin her bağlamda birbirlerinin yerini tut(a)madıklanı açıktır. Bununla birlikte eş anlamlılığın nasıl oluştuğuna dair sistematik bir çözümleme de yapılmamıștır. Bu sebeple bu çalışmada genelde Anlam Bilimi'nin özelde ise ortaöğretim Dil ve Anlatım dersi müfredatının bu mevcut sorununa sistematik bir değerlendirmeyle katkı sağlanmak hedeflenmiştir. Eş anlamlılığın oluşum nedenlerini tespit ederken alıntı (ödünçleme) kelimelerin ve dilin bünyesindeki kelimelerin yüzyıllar içerisinde farklı bağlamlarda kullanılması sonucunun etkileri madde bașı olarak belirtilmiștir.

Bununla birlikte tabu olarak kabul edilen, söylenmesi yasak veya suç sayılan, söylendiği anda kötü şeylerin olacağına inanılan; Türkçede "örtmece, iyi adlandırma, güzel adlandırma, edeb-i kelâm, hüsn-i tabir" gibi kelimelerle, Batı' da ise 'euphemısım' kelimesiyle ifade edilen kavram da incelenmiş ve inceleme sonucunda örtmece (tabu) kelimelerin de eş anlamlılığa katkı sağladığı tespit edilmiştir. Örtmece kelimelerin neden, niçin ve nasıl oluştuğunun da incelendiği bu çalışmada bir diğer amaç, örtmece kelimelerin de eş anlamlılığa olumlu katkısını açıklayarak örtmece kelimeleri eş anlamlılığın bir nedeni olarak göstermektir.
\end{abstract}

Anahtar Kelimeler: Eş anlam, anlamdaş, müteradif, örtmece, iyi adlandırma, güzel adlandırma.

\section{Synonymy and Euphemısm (Tabu) in Turkey Turkısh}

\begin{abstract}
In this study synonyms and taboo words, which is one of the study fields of Semantics, have been emphasized.

The meaning of the being synonym, which is explained with different words in language studies, is usually described by a dictionary context.Although several studies have been held synonyms are still believed as one the problematic subjects waiting for solutions.It is clear that although they are described as 'same meaning words' in dictionaries,synonyms donot/cannot always commute each other in every case.Beside this, a systematic analysis on how synonyms occured has not been done ,either. In this study, a contribution to more systematic solution fort he current problem is aimed but not to solve the whole synonym problem.

During determining the exisiting reasons of synonyms,the effects of the result of using the citation words in different contexts for ages have been emphasized.

Nevertheless,it was found out that the taboo words,forbidden words,words that bring bad events and called 'örtmece, iyi adlandırma, güzel adlandırma, edeb-i kelâm, hüsn-i tabir' in Turkish and 'euphemısım' in the West have great contribution to synonyms.Another aim of this study,in which how and why synonyms occured, is to evidence that taboo words have positive contribution to synonyms and indicate the taboo words as one of the reasons of synonyms.

Keywords: Synoym, taboo, Semantics.
\end{abstract}

\section{Giriş}

Anlam Bilimi’nin üzerinde çok tartışılan konularından birisi de eş anlamlılıktır. Kısaca "sözler arasında anlam birliği olması durumu” (TDK, 2011: 822) şeklinde tanımlanan eş anlamlılık hakkında araştırmacılar değişik açıklamalarda bulunarak bu konunun çözümlenmesi yolundaki tartışmalara devam etmişlerdir. Bu çalışmada eş anlamın nasıl ve hangi yollarla oluşmuş olabileceği üzerinde durulmuş, örtmece (tabu) kelimelerin de eş anlamlılığa katkısı örneklerle değerlendirilmiş ve bu sebeple örtmece kelimelerin de eş anlamlılığın oluşma sürecinde yeni bir madde olabileceği düşüncesi dile getirilmiştir.

\section{Konu hakkındaki görüşler}

Eş anlamlılık konusuna girmeden önce bu terimin araştırmacılar tarafından nasıl ele alındığına değinmekte yarar vardir.
Gökalp (1996: 115)'in Türkçülüğün Esasları adlı eserinde belirttiği şu görüşler konunun genel seyri açısından önemlidir: "Birincisi, halk dilinde eş anlamlı kelimeler yoktur. Halk, Arapçadan ve Acemceden bir kelime aldığ zaman onun eş anlamlısı olan Türkçe kelimeyi Türkçeden büsbütün atar. Böylelikle dilde eş anlamlı kelimeler kalmaz. Meselâ halk hasta kelimesini alınca sayru sözünü, ayna kelimesini alınca gözgü sözünü merdiven kelimesini alınca baskıç sözünü tümüyle unutmuştur. Gerçi bazen halkın Arapçadan ve Acemceden aldığ 1 kelimeler yanında eski Türkçelerini de koruduğu görülür. Mesela siyah ve beyaz kelimeleri alındıktan sonra kara ve ak kelimeleri Türkçede kalmış. Fakat ne siyah kelimesini kara kelimesinin ne de beyaz kelimesini ak kelimesinin eş anlamlısı sayamayız." Gökalp'in altını çizdiği bu hususlar, birçok araştırmacıya kaynak olmuştur.

"Eş anlamlı ya da anlamdaş dediğimiz ögeler, adları her ne kadar eş anlamlı ise de birbirinin tam eşi 
anlamına gelmezler.', şeklinde bir açıklamayla Gökalp'in görüşlerini destekleyen Aksan (1974: 1) ise her dilde görülen eş anlamlığın kimi zaman oldukça büyük, kimi zaman pek küçük anlam farklılıklarına sahip olduğunu vurgulamış, buna benzer ögelerin - baş-kafa örneğindeki gibi - yakın anlamlı kelimeler olarak değerlendirilmesini uygun görmüştür.

Korkmaz (1992: 55-56) "anlamları aynı veya birbirine yakın olan kelimeler', olarak tanımladığı eş anlamlılığın tıpa tıp denklik anlamında çok az kelimede var olduğunu belirterek kelimeler arasındaki sosyal ve dil merkezli farklılıklara değinmiş ve bu kelimelerin birbirlerine yaklaştığından bahsetmiştir. Eş anlamlılığın dilin kendi kelimeleri (bıkmak, bezmek, usanmak) arasında olabileceği gibi alıntı kelimelerden (göz, çeşm, ayn) kaynaklı bir durum olabileceğini vurgulamıştır.

Hatipoğlu (1970: 9-10) bütün dillerde eş anlamlı kelime teriminin var olduğundan bahsetmiş, ancak eş anlamlı kelimeler arasında matematiksel bir eşitliğin olamayacağını, bu kelimelerin her anlamda birbirinin yerini tutamayacağını ana-anne-valide-mader örneklerini vererek açıklamıştır.

Yukarıda görüşlerine yer verdiğimiz araştırmacıların birleştikleri ortak nokta dildeki kelimeler arasında tam eş anlamlılığın olmadığıdır. Bununla beraber bu görüşler eş anlamlılığın nedenleri hakkında da bilgi vermektedir. Buna göre eş anlamlılık ödünçleme yoluyla meydana gelebileceği gibi dilin kendi kelimelerinin yıllar içinde farklı bağlamlarda kullanılarak aynı göstergeye işaret edecek hâle gelmesiyle de oluşmuş bir durumdur.

\section{1. Ödünçlenme Sonrası Eş Anlamlılık}

Ödünçlemek Türkçe Sözlük (2011: 1837)'te ' başka bir dilden söz almak, bütünüyle özümsemek" olarak tanımlamaktadır. Aksan (2000c: 25) "Diller arasındaki ilişkiler sonucunda bir dilden ötekine geçen ögelerin başında, kelimelerin geldiği görülür. $\mathrm{Bu}$ durumun ortaya çıkışında, toplumlar arasındaki ilişkilerde, belli mallara, araç ve gereçlere, kişiye ve topluma ilişkin kavramlar olarak kelimelerin, dilin ses, biçim, sözdizimi ögelerinden daha çok yer almaları etkili olmuştur.', diyerek ödünçlemenin doğal bir süreç olduğundan bahsetmiştir.

Doğal bir süreç olan ödünçleme sonucu dil kendini sürekli güncel ve dinamik tutmaktadır. Diller arasında da kelimeler aracılığıyla alışveriş yapılmaktadır. Toplumların etkileşim ve iletişim aracı olan, topluluğun her türlü kültür, sanat ve din değişimlerinden etkilenen, topluluğun değişen ihtiyaçları veya topluluğun bilinmeyen nesneleri kullanmaya başlama gibi nedenlerinden ötürü başka dillerden kelime ödünçleyen dil, toplumun adeta en değerli antika eşyas ${ }^{1}$ konumundadır. Dilin bünyesindeki kelimeler toplumun etkileşime girdiği diğer kültürler hakkında, geçirdiği evreler ve değişimler hakkında bize bilgi veren en önemli unsurdur.

Dil sadece portakal, patates, çay, kahve, şeker gibi kendi bünyesinde olmayan kelimelerin, kavramların karşılıklarını ödünçlememektedir. Bununla birlikte dil, aynı zamanda kendi haznesini genişletmek ve dolayısıyla anlam genişliği

\footnotetext{
${ }^{1}$ Bu ifadeyi Ragıp Hulusi Özdemir “...dilde yadigâr kalmış bu gibi yabancı sözler de yerli dil sahiplerinin kendileriyle kültür temaslarında bulunduğu türlü medeniyet çerçevelerinin izlerini arzeder.” şeklindeki açıklamasında kullanmıştır.
}

sağlamak için de başka dillerden ödünçleme yapmaktadır. Bunun da farklı nedenleri vardır. Özellikle Divan Edebiyatında sanat yapabilmek ya da estetik zevk gibi nedenlerin yanı sıra vezin ve kafiye gibi nedenlerden dolayı bir sözcüğe, göstergeye, kavrama alternatif birden fazla kelime bulunmaktadır. Güneş sözcüğü yerine şems (Ar.) ve afitab (Far.); göz sözcüğü yerine çeşm ( Far.) ve ayn (Ar.); su yerine ab (Far.); ay yerine mah (Far.) ve kamer (Ar.) sanat, estetik veya vezin gözetilerek ödünçlenen kelimelerdir.

Toplumların din değişikliği de ödünçlenmenin önemli bir başka nedenidir. İslamiyet öncesi dönemde Tengri/Tanrı kelimeleri kudret sahibi, tapınılacak veya dua edilebilecek tek varlığı karşılarken İslamiyet'ten sonra Allah, İlah, Rab gibi kelimelerin de kudret sahibi, tapınılacak veya dua edilebilecek tek varlığı karşılayacak şekilde ödünçlenmesi de din etkisini açıkça gösterir. Bu kelimeler her ne kadar birbirinin yerine kullanılsalar dahi anlam yoğunluğu bakımından birbirlerinin yerini aynılıkla karşılamazlar. Bu sebeple günümüzde bile hem Tanrı hem de Allah sözcüğü birlikte kullanılmaktadır.

Ödünçlenen her kelime kendinden önceki sözcüğü unutturmamaktadır. Bunun en temel nedeni halkın yüzyıllardan beri kullanılageldiği bu kelimelerin artık bazı bağlamlarda sabitlendiğidir. Bu konumdaki bir kelimenin üzerine gelen ödünçleme zihinlerde o bağlamın yerini tam olarak karşılayamayacağı için güç savaşına girmez. Ödünçlenen kelimeler de farklı bağlamlarda kullanılmak şartıyla varlığını devam ettirmektedir.

Gökalp (1996: 115) halkın ödünçlenen kelimelerle birlikte ana diline ait olanları da kullanmaya devam ettiğini söyler. Ayrıca ödünçlenen kelimelerle dilde var olanlar arasındaki anlam farklılıklarına da dikkat etmek gerektiğini belirtir. "Zira kimi zaman alıntı sözcükte kimi zaman da ana dile ait sözcükte meydana gelen değişiklikler eş anlamlılığı ortadan kaldırabilmektedir. Söz gelimi siyah ve beyaz sözcükleri alındıktan sonra kara ve ak kelimeleri Türkçede kalmış, fakat ne siyah sözcüğü kara sözcügüunün ne de beyaz sözcüğü ak sözcüğünün eş anlamlısı olmamıştır.', Gökalp'in verdiği örnekler şu şekilde değerlendirilebilir: Kara talih ifadesi artık kalıplaşmış bir ifade olduğu için siyah talih diyemeyiz veya ananın ak sütü gibi helal olsun ifadesi yerine ananın beyaz sütü gibi helal olsun diyemeyiz.

Bütün dillerde eş anlamlılığın varlığından bahseden Hatipoğlu (1970: 9-10) bu kelimelerin her anlamda birbirinin yerini aynılıkla karşılayamadıklarını şu şekilde açıklamıştır: "Yüz, surat, çehre, sima" sözcükleri de eş anlamlı gibi görünür. "Yüzü yabanc1 değil” sözünde "yüzü” sözcüğünün yerine "suratı, çehresi, siması" kullanılabilir ama, bu sözcüklere "-siz" yoksunluk eki getirilince başka başka anlamlar ortaya çıkar: "Yüzsüz", "arsız" anlamında, "suratsız" "asık suratlı, abus" anlamında kullanılır. Ötekiler de "çirkin" anlamında kullanılabilir." Hatipoğlu'nun verdiği örnek kelimelerin etimolojisine bakıldığında "çehre" kelimesinin Farsça (Ayverdi, 2000a:542), "sima" kelimesinin Arapça (Ayverdi, 2000c:2798), "surat" kelimesinin Arapça (Ayverdi, 2000c:2860) kökenli olduğu, “yüz" kelimesinin ise Eski Türkçeden (Ayverdi, 2000c:3458) beri kullanıldığı sonucu karşımıza çıkmaktadır.

Ödünçlenerek dile yerleşen kelimeler de dilin anlam genişliliğini arttırmaktadır. Al, kızıl ve kırmızı kelimelerini incelediğimizde kızıl sözcügünün Eski Türkçede parlak 
kırmızıyı "Kızıl havaları seyret ki akşam olmakta, Ahmet Haşim” (Ayverdi, 2000b:1701), al sözcüğünün Eski Türkçede pembeye kaçan parlak kırmızı renk "Al kanların içinde kaldın Cemalim” (Ayverdi, 2000a:84), kırmızının ise Arapça al ve kızıl renkleri karşılayan kelimeler (Ayverdi, 2000b:1684) olduğunu görürüz. Renkler arasındaki yoğunluk fark1 ve dilde bulunma süreleriyle orantılı olarak bu kelimlerin aynı rengi karşılasalar bile her bağlamda birbirlerinin yerini aynılıkla karşılayamadıklarını şu şekilde belirtebiliriz:

Bir kızıl goncaya benzer dudağın.

Bir al goncaya benzer dudağın.

\section{Bir kırmızı goncaya benzer dudağın.}

$\mathrm{Bu}$ görüşler ve verdiğimiz örnekler eş anlam olarak bilinen durumun ödünçlenme şeklinde oluşabileceğini ortaya koymaktadır. Ödünçlenerek dile yerleşen kelimelerin de artık halka mal olmuş kelimeler olduğu düşünülürse bu tür kelimeler dilin anlam genişliğini ve anlatım gücünü arttırmaktadır.

\subsection{Yerli Kelimelerde Eş Anlamlılık}

Aksan (2000:190)' 1n 'Dilin ifadeyi en basit ve en rahat söyleme özelliğinden dolayı hiçbir dil başlangıçta bir nesne, durum veya olayı işaret edebilmek için birden fazla sözcüğe ihtiyaç duymaz. Bu nedenle birbirinin tam aynı, eşi anlamına gelen birden fazla yerli sözcüğün bulunmadığı" düşüncesi kabul gören bir görüştür. Çünkü bir dilde, bir kavrama bir kelime ilkesi genel olarak belirlenen bir ilkedir.

Kelimeler yüzyıllar içerisinde kullanıldıkları değişik bağlamlardan dolayı birbirlerine yaklaşmaktadırlar. $\mathrm{Bu}$ durumda ise kelimelerin-çok uzun bir süreyi kapsayankullanımı sırasında çok anlamlılık veya alt anlamlılık ortaya çıkmaktadır. Bu şekilde çok anlamlı veya alt anlamlı kelimeler arasında mecaz ve ima yoluyla kesişmeler, çakışmalar veya geçişmeler görülmekte(Erdem 2004:160) ve bu şekilde de yerli eş anlamlılık ortaya çıkmaktadır.

Dilin bünyesindeki yerli kökenli eş anlamlıların bolluğu dilin anlatım gücünü arttırmaktadır. Bu görüşümüzü alınmak, darılmak, gücenmek, incinmek, kırılmak, küsmek kelimelerinin iki farklı kaynağa göre incelendiğimizde karşımıza çıkan şu sonuçlarda görülmekteyiz:

\section{alınmak:}

M.B.T.S ${ }^{2}$ : (Bir sözden, bir davranıştan) Kendine göre anlam çıkararak incinmek, gücenmek. "Teessürümü gizleyemiyorum, doktor bundan alınmış gibi görünüyor." - $\mathrm{P}$. Safâ (Ayverdi, 2006a:104)

T.S ${ }^{3}$ : -e, -den Bir sözün, bir davranışın kendisine söylediğini veya yapıldığını sanarak incinmek, kırılmak "Emekli ajan, alınmış gibi maun masanın arkasında oturan kişiyi süzdü." - O. Aysu (TDK 2011: 94)

\section{darılmak:}

M.B.T.S: Eski Türk. taru-mak "daralmak; canı sıkılmak' 'tan, 1. Gücenip görüşmez olmak, küsmek. "Çocukların ölümünden sonra mahalleye darılmış."-R. N. Güntekin; 2. Kızmak, alınmak "Fikriye, darılma ama çok saf, çok bön karısın.”-H.R. Gürpınar; 3. Azarlamak, paylamak “Ay, ne darıliyorsun?” -N. Kemal (Ayverdi, 2006a: 633)

T.S: 1. Hoşa gitmeyen bir tutum, davranış veya söz dolayısıyla gücenip görüşmez olmak, gücenmek, küsmek, ilgiyi kesmek "Kalenin üzerine top atmadılar bahanesiyle darılmadı mıydı?"-Ö. Seyfettin 2. Gücenmek, kırılmak, alınmak, incinmek "Kendisine uygulanan bu tavırdan ne darılmıştı ne gücenmişti."-N. Araz 3. Azarlamak, paylamak. (TDK 2011: 1564)

\section{gücenmek:}

M.B.T.S: Eski Türk. küç “şiddet, zulüm”'den küç+e-mek “"zulmetmek”(bir söz veya davranıştan dolayı) bir kimseye kırılmak, darılmak. "Sözlerin acı diye kızım gücenme bana"F. N. Çamlıbel (Ayverdi, 2006a: 1103)

T.S: nsz, -e Birinin beklenilmeyen bir davranışı veya sözü karşısında kırgınlık duymak, kırılmak "Kendisine uygulanan bu tavırdan ne darılmıştı ne gücenmişti." - N. Araz (TDK 2011:994)

\section{incinmek:}

M.B.T.S: Gönlü kırılmak, gücüne gidip üzülmek. "Böyle sözlerle bil ki incinirim."- H.F. Ozansoy (Ayverdi, 2006b:1406)

T.S: den Birinin herhangi bir davranışı yüzünden üzüntü duymak, gücenmek, kırılmak (TDK 2011: 1189)

\section{kirılmak:}

M.B.T.S: (mec.) İncinmek, gücenmek, rencide olmak. 'Çünkü Murat'ın kırılmasına ben sebep olmuş olacağım, Aka Gündüz.'’(Ayverdi, 2006b: 1680)

T.S: -e Birine karşı kırgın duruma gelmek, gücenmek, incinmek. (TDK 2011: 1415)

\section{küsmek:}

M.B.T.S: Eski Türkçeden beri kullanılır. Darılmak, gücenmek, gücenip görüşmez olmak. "Küstürdüm güzeli güldüremedim/Küsme güzellerin şahı isen de" Karacaoğlan',(Ayverdi, 2006b: 1831)

\section{T.S: Darılmak. (TDK 2011: 1564)}

Türkçe Sözlük'ün ve Misalli Büyük Türkçe Sözlük’ün açıklamalarına bakıldığında en geniş anlamın "darılmak" olduğu görülmektedir. Bunun bir nedeni de kelimenin Eski Türkçeden beri kullanılmasıdır. Bu kullanım eskiliğinden dolayı unutulmamış ve başka yan anlamlara da bürünerek günümüze kadar ulaşmıştır. Bunun yanı sıra "küsmenin" "darılmakla" aynı anlama geldiği ve bazı kelimelerin de farklı bağlamlarda kullanılarak mecaz anlama bürünmek suretiyle bu anlamı karşıladığı görülmektedir.

Dilin işlenmişliği ve sanatlı söyleyiş özelliği açısından da eş anlamlılık son derece önemlidir. Yabancı kelime sayısının

\footnotetext{
${ }^{2}$ Misalli Büyük Türkçe Sözlük

${ }^{3}$ Türkçe Sözlük
} 
$\% 1$ 'in altında ${ }^{4}$ olduğu ilk yazılı metinlerimiz olan Orhun Abidelerinde dilin işlenmişliği dikkat çekerken, eş anlamlı kelimeler de karşımıza çıkmaktadır. Saygı duyulan, yaşamı boyunca değerli sayılan kişilerin ölümlerine değer kazandırmak için "kergek bolmak", "uça barmak" kelimeleri kullanılırken, düşman ya da avamdan olanların ölümünü ifade etmek için de "ölti”, kelimesi kullanılmıştır" . "Öl-" fiilinin bu haliyle üç şekli vardır:
a) kergek bol-:
b) uça bar-:
c) öl-:

Konunun başında da belirtildiği gibi eş anlamlılık Anlam Bilimin üzerinde tartışmalı olduğu bir konudur. Konun tartışmalı olması, bu zamana kadar farklı zamanlarda açıklamalar yapan araştırmacıların yukarıda örneklerle açıkladığımız eş anlamlığın oluşması yönündeki nedenlerini sistematik bir şekilde ortaya koymamalarındandır. Buraya kadar bu iki bölüm sistematik bir şekilde ele alınarak incelenmiş, örneklerle açıklanmaya çalışılmış ve eş anlamlılığın oluşumu için ilk iki madde olması önerilmiştir.

Farklı bağlamlarda, farklı anlamlarda kullanılmak suretiyle bir kelime başka bir kelimenin yerini mecaz veya anlam değişmesi yoluyla karşılayabilir. Bu da eş anlamlılığın oluşum sürecini etkileyen bir durumdur. Bununla birlikte ödünçlenen kelimelerin anlam ilişkisi yönünden yüzyıllar içerisinde kullanılması o kelimelerin halk tarafından özümsendiğini göstermektedir. Bu durum ise eş anlamlığın oluşumuna bir başka nedendir.

\section{3. Örtmece (Tabu) Kelimelerde Eş Anlamlılık}

Tabu, insanlığın yazılmamış en eski yasası olarak yasaklarla ortaya çıkan, bu yasakların ihlali ile aynı ceza sistemlerini doğuran, bu içerikten çıkan yasağın türünü, yasağın çiğnenmesi sonucu ortaya çıkan kutsallığı ya da kirliliği anlatır. Tabu ve tabuya dayalı ortaya çıkan örtmece sözler arasındaki ilişkiyi doğuran sebep-sonuç ilişkileridir. Çünkü örtmece sözleri de ortaya çıkaran tabudur. Bu nedenle tabu ve örtmece sözler birbirleriyle sıkı sıkıya bağlıdır. Kısacası örtmece sözleri yaratan en önemli etkenlerden biri tabudur. (Güngör, 2006: 29)

Örtmece konusu gerek batılı gerekse Türk dünyası bilim adamlarınca dil-kültür bağlamında sosyolojik, psikolojik ve etnolengüistik açıdan araştırılmış, bu alanla ilgili terminolojiyi de yaratmışlardır. Türkiye'de bu alandaki araştırmalar ise genelde folklorik derlemelerden öteye gidememiştir. Söz konusu alanda dilbilimsel değerlendirmelere ihtiyaç duyulduğu kuşkusuzdur. (Güngör, 2006: 29)

Aksan (2000: 100), güzel adlandırma, iyi adlandırma, örtmece terimleriyle tanımladığı euphemism için "kimi varlıklardan, nesnelerden söz edildiğinde doğacak korku, ürkme, iğrenme gibi duyguların, kötü izlenim ve

\footnotetext{
${ }^{4}$ Doğan Aksan'ın araştırmaları sonucuna dayanılarak verilmiş bir değerdir. Ayrıntılı bilgi için, Türk Dili XXXVI(1977), No.313,344-347

${ }^{5}$ Örtmece(tabu) kelimelerin eş anlamlığa etkisi maddesinde de bu durum üzerinde durulmuş ve gerekli örnekler verilmiştir.
}

çağrışımların önlenmesi amacına yönelen ve dünyanın her dilinde rastlanan bir değiştirme olayı" olarak ifade eder.

Üstüner'in (2009: 167) "Bilindiği gibi, anlamı ve çağrışımı sevilmeyen, korkulan, iğrenilen; toplum tarafından üzücü, kırıcı, çirkin ve kaba sayılan, uğursuz kabul edilen varlık ve kavramları karşılayan kelimeler yerine, bu kötü çağrışımları engelleyecek başka kelimelerin kullanılmasına güzel adlandırma veya örtmece söz adı verilir. Toplumun ahlâki, dinî ve örfî değerlerine aykırı olduğu için söylenildiğinde korku, ürkme ve iğrenme gibi kötü izlenimler uyandıran ve bu sebeplerle söylenmesi uygun görülmeyen varlık, kavram ve davranışlar, dildeki yaygın karşılıkları yerine, doğabilecek kötü izlenimleri engelleyen, hoş karşılanabilen aynı anlam yüklenmiş başka kelime veya sözlerle anlatılarak bu kötü etki en aza indirilmeye çalışılır." şeklindeki açıklaması konun genel seyri açısından önemlidir.

Benzer bir şekilde Erol'un (2002: 35) "Yasaklanmış bir şeyi ifade eden tabu, örtmecenin doğmasina neden olmaktadır. Örtmece, nesnenin veya olgunun adını doğrudan söylemek kaba veya ayıp olduğunda, onu yumuşak ve nazik sözlerle değiştirerek kullanmaktır. Bir başka deyişle örtmece, şekli değişmiş tabu veya doğrudan söylenmesi yasak olan anlamın görüntüsüdür. Tabu sadece yasağı değil, kutsal bir şeyin de söylenmemesi olarak değerlendirilebilir." şeklindeki açıklaması da, örtmece-tabunun merkez bir nesne, olay veya durum (tabu) etrafında gerçekleşen ve bu merkez nesneyi, olayı veya durumu (tabuyu) söylemeden ona işaret edecek kelimelerin ortaya çıkarılması şeklinde oluştuğu sonucunu karşımıza çıkarmaktadır.

Örtmece kelimeler zaman içerisinde yerine kullanıldıkları sözcüğü çağrıştıracak duruma gelebilmektedir. Bu durumda ise dil yeni örtmeceler arar. Faiz sözcüğü nema, sözcüğüyle örtülürken günümüzde ise vadeli mevduat, kâr payı, gecikme zammı kelimeleriyle örtülenmektedir. Örtmece kelimelerin bu şekilde sürekli güncellenmesi, dile yeni kelimelerin kazandırılması veya mevcut kelimelere yeni anlamlar yüklenme sürecinin bir süreklilik halini almasına neden olmaktadır.

Konuyu daha da somut hale getirmek için şu örnekler üzerinde durmak yerinde olacaktır:

“ 'Ölmek” eylemi zihinlerde yarattığı çağrışım sebebiyle bu eylemin kime uğradığına bakılarak farklı şekillerde ama “ölmek, ölüm”, ifadesi kullanılmadan çok geniş bir ifade şekliyle dile getirilmiştir. Daha ilk yazılı metinlerimiz olan Köktürk metinlerinde dahi "ölmek" eylemi bu durumun kime uğradığına bakılarak değerlendirilmiştir. 'Kül Tigin özi ança kergek boldı. Kangım kagan uçdukda...' ve "Türgiş budunug anda ölürmiş, almış." (Ergin 2011:18,22) Kültigin ve Kağanın ölümü kergek bol- veya uç- fiilleriyle ifade edilirken Türgiş boyunun ölmesi öl- fiili ile açıklanmıştır. Buna paralel olarak ölme eylemine maruz kalan kişinin ölmeden önceki hayatı ve yaşayanlar üzerinde bıraktığı izlenim de ölme üzerine oluşturulan örtmece kelimelerin oluşumunda önemli derecede etkilidir. Günümüzde de sözlüklere bakıldığında ölümün ahirete gitmek, ahirete göçmek, ahiret yolculuğuna çıkmak, adres değiştirmek, , can borcunu ödemek, can vermek, cortayı çekme, dar-1 bekaya irtihal etmek, dünyadan ayrılmak/göçmek, dünyasını değiştirmek, dünyaya gözlerini kapamak/yummak, dünyaya veda etmek, ebediyete göçmek, ebediyete(sonsuzluğa) intikal etmek, emrihak vakî olmak, ecel şerbetini içmek, gebermek, 
günü dolmak, Hakk'a yürümek, mevta, nalları dikmek, ömrü vefa etmemek, ömür defterini kapatmak, son nefesini vermek, tahtalı köyü boylamak rahmetli olmak, rahmet-i rahmana kavuşmak, ruhunu teslim eylemek, toprak olmak, vadesidolmak/gelmek/yetmek, vefat etmek yaşamını yitirmek/kaybetmek gibi değişik anlamlara gelecek şekilde kullanımları görülmektedir. Yukarıdaki açıklamalara bakıldığında örtmece kelimelerin ödünçleme, mecaz anlam, deyimleşmiş ifade ve argo yoluyla yapılabileceği karşımıza çıkmaktadır.

Cinselliği çağrıştığı gerekçesiyle ayıp karşılanan hamilelik yüklü, gebe, gunlacı ${ }^{6}$, orta kata kiracı gelme, eve kalıcı misafir gelme gibi bir örtmecelerle ifadelendirilmiştir.

Anadolu'da ve diğer Türk topluluklarında albastı tabusunu söylemek yerine al, al-ana, al-karı, al-kuzu, martu, sarı-kı, kir-köylek, atsız gibi örtmece kelimeleri kullanılmıştır.

Hastalık isimlerinde de örtmece karşımıza çıkmaktadır. Verem hastalığına karşı söylenen ince hastalık, diyabet hastalığına karşı söylenen şeker hastalığı birer örtmece olarak karşımıza çıkar.

Adları anıldığı zaman kötü şeylerin başa geleceğini düşündüren varlıkların adları artık tabu olmuştur. Cin yerine üç harfli, buradan uzak olsun gibi örtmeceler kullanılırken, Azrail için ölüm meleği veya ecel meleği örtmeceleri kullanılmaktadır.

Dinî değerlerde aynı şekilde tabu sayılmıştır. Allah yerine Rab, Rahman, İlah..., Kuran-1 Kerim yerine Mushaf, Allah Kelamı/Kelamullah gibi örtmeceler kullanılmıştır.

Örtmece kelimeler zihinlerde net olan bir kavram veya durumun biraz daha yumuşatılarak, güzelleştirilerek veya ima edilerek söylenmesidir. Analojik olarak ele alındığında eş anlamlılık da zihinlerde var olan nesnelerin, durumların veya eylemlerin farklı şekillerde ifade edilmesi durumu olduğuna göre örtmece kelimeler de eş anlamlılığın oluşmasına önemli katkı sağlamaktadırlar.

\section{Sonuç ve Öneri}

Dil, toplumların yaşayan en önemli kültür unsurlarından birisidir. $\mathrm{Bu}$ sebeple toplumların kültürel miraslarını inceleyen araştırmacıların ilgilendiği ilk unsur dil, nihayetinde ise kelimelerdir. Dil araştırmacılığı dilin değişken ve canlı yapısından dolayı kesinlik arz etmemektedir. Ancak bu durum, bu konuyla ilgili kesin sonuçlara ulaşılamayacağı sonucunu da doğurmamaktadır. Toplumların yüzyıllar boyunca yoğurarak günümüze kadar getirdikleri dil özellikleri günümüz dil araştırmacıları tarafından araştırılmaktadır. Bu araştırmaların bir kısmı bir sonuca bağlanabilirken bir k1smı da kesin sonucu belirtmekten uzaktır. Sonuçlandırılamayan araştırmalar genellikle farklı araştırmacılar tarafından ortaya konan benzer düşüncelerin bir potada eritilemediği ve sistematik bir sonucun ortaya çıkarılamadığı çalışmalardır.

Yaptığımız çalışmalara ve araştırmalara göre Türkiye Türkçesi için kesin bir sonuca ulaşılamayan konulardan birisi de eş anlamlılıktır. Eş anlam konusunun kesin bir sonuca

\footnotetext{
${ }^{6}$ Yüksek Lisans Tezi için Boynuinceli Yörükleriyle yaptığım röportajlar sırasında tespit ettiğim bir kullanımdır.
}

ulaştırılamaması genelde Anlam Bilimi çalışmalarını, özelde ise ilk ve ortaöğretim Türkçe dilbilgisi konularını olumsuz etkilemektedir. Özellikle soyut düşüncenin ve muhakeme kabiliyetinin güçlendiği; buna paralel olarak bağlam-anlam ilişkisinin kazanıldığ 1 ortaöğretim seviyesinde eş anlam konusu müfredatta beyaz-ak, siyah-kara, kırmızı-al şeklindeki örnekleriyle öğrencilerin zihinlerinde daha bulanık bir hale gelebilmektedir. Hatta bazı öğrenciler bu tür kelimelerin eş anlamlı değil, yakın anlamlı olması gerektiğini bile dile getirmektedirler. Bu sebeple, eş anlamlılıkla ilgili yapılan değerlendirilmeler bir potada birleştirildiğinde dil araştırmacılarının eş anlamlılığı sadece ortak bir kavram olarak kullandıkları, hiçbir sözcüğün bir diğeri sözcüğü aynılıkla karşılamayacağı sonucuna vardıkları tespit edilmiştir.

Temelde ödünçlenen kelimelerle yerli kelimelerden kaynaklandığ 1 üzerinde hemfikir olunan eş anlamlılık, örtmece kelimeler sonucu da ortaya çıkmaktadır. Ağızlar, argo kullanımlar ve tabu düşünceler sonucu bolca kullanılan örtmece kelimelerin de dilin kelime haznesine oldukça fazla bir şekilde eş anlamlı kelime kazandırdığı çeşitli araştırmalar sonucu ortaya çıkarılmıştır. Bu sebeple eş anlamlılık üç farklı şekilde ortaya çıkabilmektedir. Çalışmamız sonucunda konunun daha sağlıklı bir zeminde değerlendirilebilmesi için eş anlam sınıflandırma önerisi şu şekilde oluşmuştur:
A- Ödünçlenme Sonrası Eş Anlamlılık
B- Yerli Kelimelerde Eş Anlamlılık
C- Örtmece (Tabu) Kelimelerde Eş Anlamlılık

\section{Kaynakça}

AKSAN, Doğan (1974), Eş anlamlılık Sorunu ve Türk Yazı Dilinin Saptanmasında Eş anlamlılardan Yararlanma, Türkoloji Dergisi, Ankara Üniversitesi, Ankara, 6.Cilt, 1.Say1, Syf. 1

AKSAN, Doğan (1999), Anlam Bilim, Engin Yayınevi, Ankara, Syf. 80

AKSAN, Doğan (2000), Her Yönüyle Dil, Ankara, 3. Cilt, Syf.45, Syf.190

AYVERDİ, İlhan (2006), Misalli Büyük Türkçe Sözlük, Kubbealtı Neşriyat

DOĞAN, Nuh (2011), Türkiye Türkçesi Fiillerinde Eş Anlamlılık, Uluslararası Sosyal Araştırmalar Dergisi, 4.Cilt 19. Say1, Syf.78-88

ERDEM, Melek (2004), Oğuz Grubu Türk Lehçelerinde Eş Anlamlılık(Synonym), Zeynep Korkmaz Armağanı, TDK Yayınları: 853, Syf.147

ERGIN, Muharrem (2011), Orhun Abideleri, Boğaziçi Yayınları, 2011

EROL, Hülya Arslan (2002), Tabu ve Kelimelerin Anlam Alanlarına Etkisi, TDAY-II Syf.35-56

ERSOY, Ruhi (2002),Türklerde Ölüm ve Ölü İle İlgili Rit ve Ritüeller, Milli Folklor, 54. Say1, Syf.86-101

ERSOYLU, Halil (2001), Eş Anlamlılık mı, Yabancı Kaynaklı Karşılık Oluş mu? Türk Dili, 59. Sayı 
GÖKALP, Ziya (1996), Türkçülüğün Esasları, Kamer Yay., Syf.115

GÜNGÖR, Ahmet (2006), Tabu- Örtmece (Euphemism) Söz Üzerine, Atatürk Üniversitesi. Türkiyat Araştırmaları Enstitüsü Dergisi, Erzurum, 29. Say1

HATİPOĞLU, Vecihe (1970), Eş anlamlı Sözcükler Var mıdır? Türk Dili, Ankara Üniversitesi Basımevi, Ankara, 23. Cilt 229. Say1

KORKMAZ, Zeynep (1992), Gramer Terimleri Sözlüğü, Ankara, TDK Yayınları, Syf. 55

SARI, Mustafa (2011), Türkiye Türkçesinde Eş Anlamlılık İle İlgili Bazı Sorunlar, Turkish Studies, Volume 6/1, Winter, P. 523-528.

TOPARLI, Recep(2000), Ragıp Hulûsi ÖZDEM, Dilimizde Yerleşmiş Yabancı Unsurlar, Syf. 408

Türk Dil Kurumu(2011), Türkçe Sözlük, Ankara, TDK Yayınları

ÜSTÜNER, Ahat (2009), Örtmece Sözlerle İlgili Terimler, Turkish Studies, Volume 4/8, Fall 2009

ZÜLFİKAR, Hamza (1990), Eş Anlamlılık ve Ziya GÖKALP'in Eş Anlamlılık İle İlgili Düşünceleri, Türk Dili, Say1:463 